\title{
VII \\ Las esculturas de Rapa Nui (Isla de Pascua) en el Museo Etnográfico de Buenos Aires
}

\author{
Daniel Schávelzon y Ana Igareta
}

\section{Resumen}

En el Museo Etnográfico de la Universidad de Buenos Aires existen desde inicios del siglo XX diversas figuras de madera provenientes de la Isla de Pascua, pero por diversos motivos casi no han sido dadas a conocer. Salvo un par de ellas publicadas el resto ha permanecido guardado, quizás por el peso que José Imbelloni le dio al tema entre 1930 y 1950, lo que produjo un fuerte rechazo a volver a tocar esos problemas connotados de política racista. Es nuestro objetivo el dar a conocer cada figura y describirla para que incrementen el corpus mundial de objetos históricos de los Rapanui.

\begin{abstract}
In the Ethnographic Museum of the University of Buenos Aires there since the early twentieth century various wooden figures from Easter Island, but for various reasons hardly they have been disclosed. Except for a couple of them published the rest has been saved, perhaps by the weight Jose Imbelloni gave the topic between 1930 and 1950, which produced a strong rejection to touch those figures, used to justify notorious his racist ideology and archaeological postures on the difusionnist history. It is our aim to publicize each figure and describe it to increase the global corpus of historical objects of the Rapanui.
\end{abstract}

\section{Introducción}

En el Museo Etnográfico de Buenos Aires existe una colección de esculturas de madera provenientes de Rapa Nui, que no fue dada a conocer completa nunca aunque algunas de sus piezas ya han sido publicadas y/o exhibidas. Todas menos una de las que tenemos datos ingresaron al museo entre 1911 y 1916, según indican las fichas del Museo de que se dispone, catálogo que dista de llegar siquiera a la mitad de ellas. Dos ejemplares fueron donados por la Academia de Filosofía y Letras de Santiago de Chile y una tercera pieza ingresó en 1947 proveniente en 1938 del Museo de Ciencias Naturales Bernardino Rivadavia. Al parecer el resto fue adquirida aunque no sabemos dónde ni a quien en esa época temprana de la arqueología del lugar. Es más, creemos que las que no tienen inventario es o por omisión, o dado que entraron cuando Marcelo Bórmida viajó a la isla en 1950 bajo el ampuloso título de "Expedición a la Isla de Pascua" y las compró allí. La información que encontramos en el museo es poca, pero de lo que hay, al menos da cierta certeza de fechamiento a nuestras conclusiones, tanto en las más viejas como las posibles más modernas.

En diferentes oportunidades algunas tallas han sido exhibidas: el sitio web del Museo muestra una vitrina con tres de ellas, pero otras fotografías del mismo museo ${ }^{1}$, indican que han habido cuatro piezas, habiéndose removido el Moai Kava Kava más significativo ${ }^{2}$. Las dos esculturas que se han difundido fueron publicadas hace tiempo por José Imbelloni y por Alfred Metraux. Imbelloni publicó varias en sus artículos desde 1930 pero las reproducía de otros libros y no lo decía: pese a que habían varias en el museo

\footnotetext{
${ }^{1}$ http://museo.filo.uba.ar/un-recorrido-por-el-museo-en-10-objetos . Acceso 20 marzo 2016

2 https://en.wikipedia.org/wiki/Easter_Island y https://en.wikipedia.org/wiki/Juan_B._Ambrosetti_Museum_of_Ethnography, Acceso 10 de marzo 2016
} 
usaba las de otros, lo que resulta inexplicable. Pero regresando a Metraux, dado que la mayor parte de su carrera como investigador la hizo en Argentina y que desde aquí surgió su estudio en la isla, debió conocer estas figuras aunque le debe haber sido complejo acceder a su estudio por las diferentes formas de pensar de ambos investigadores. Su expedición a Rapa Nui fue organizada desde Argentina, para ir a Honolulu para ser contratado por la universidad local y luego partir hacia la isla. No hay más referencias importantes a estas figuras, en especial en los libros que trataron de compendiar todo lo accesible en su tiempo como fue el de Stephen Chauvet de 1936. Seguramente la fuerte presencia de José Imbelloni y la tradición de mantener todo cerrado para su propio usufructo -que ni siquiera hacía uso de él-, privó el que estos objetos se integraran al corpus internacional de conocimientos, lo que sólo en forma reciente se está logrando.

Hay algunas piezas de las que no hemos logrado obtener buenas fotografías, ni siquiera regulares, pero para mantener el catálogo completo hemos utilizado lo que hemos logrado. Pedimos disculpas al lector por este inconveniente que no estuvo en nuestras manos el solucionarlo.

\section{Los objetos de madera de Rapa Nui, su estudio e interpretación}

Las colecciones de objetos de Rapa Nui se han difundido mucho gracias a Internet y al auge que el conocimiento de la isla ha tenido en los últimos veinte o treinta años, lo que generó publicaciones y exhibiciones. Durante mucho tiempo estas colecciones estuvieron guardadas en museos, no bien comprendidas y opacadas por otras culturas de mayor fuerza determinada por el eurocentrismo imperante

No sabemos con exactitud cuándo viajó la primera figura de madera de Pascua hacia Occidente. El primero en hablar de ellas fue James Cook en sus viajes del siglo XVIII y llevó algunas a Gran Bretaña, iniciando el interés por ellas. El obispo Jaussen en Tahití fotografió una de ellas en su pequeña colección en la década de 1860. Y con las ediciones de los viajes de William Geiseler en 1883 y de Edward Thompson en 1886 se cerró la etapa en que salieron las piezas más antiguas y significativas ${ }^{3}$. Sabemos que muchos turistas o viajeros casuales, incluso balleneros o barcos que recorrían el Pacífico por diversos motivos, también se llevaron sus exóticos recuerdos.

Actualmente y por consenso se consideran como "originales", a las que Thor Heyerdhal llama "funcionales", ya que todas las demás eran copias o al menos se inspiraban en ellas. Incluso hace la historia del primer Kava kava y su impacto a toda la serie posterior. Por eso se ha consensuado el usar para exhibir o estudiar a las esculturas que puedan ser rastreadas entre el siglo XVIII y la década de 1860. Esto se funda en que fueron esos últimos años cuando comenzaron a hacerse para el consumo externo, habiendo perdido su valor simbólico con la cristianización. De todas formas se considera que hasta los inicios del siglo XX y tomando como marcador, arbitrario pero concreto, el viaje de Katherine Routledge de 1914-15, hubo una época en que la creatividad de los artesanos, ya no artistas para muchos, se mantenía como sobrevivientes de una civilización destruida. Esta idea ya las hemos discutido en otros textos y obviamente implican una postura ante la creatividad que no todos aceptamos. A partir de allí lo que se considera es que hubo buenos y malos artesanos y sin duda que es tema de discusión el qué significa ser un buen artesano. Resultan muy interesantes en este aspecto las figuras con gorra militar, muy abstractas obviamente, como las publicados por J. MacMillan Brown en 1924․

La bibliografía sobre la isla se ha centrado durante su primer siglo en los grandes colosos de piedra, y con razón, son realmente una obra humana excepcional. Pero eso opacó otras formas de expresión, menores en tamaño, que si bien sabemos que sirvieron como símbolos de culto y trasmisión de tradiciones, creaciones de nivel estético ante cualquier tipo de mirada. Por supuesto que al ser de un material perecedero llegaron pocos ejemplares

\footnotetext{
${ }^{3}$ Thomson, op. cit. Geiseler, William. Die Oster Island, eine state prahistorischer cultur in der Sudsee, Berlin: Siegfrieb Mittler und John, 1883.

${ }^{4}$ MacMillan (1924), op. cit.
} 

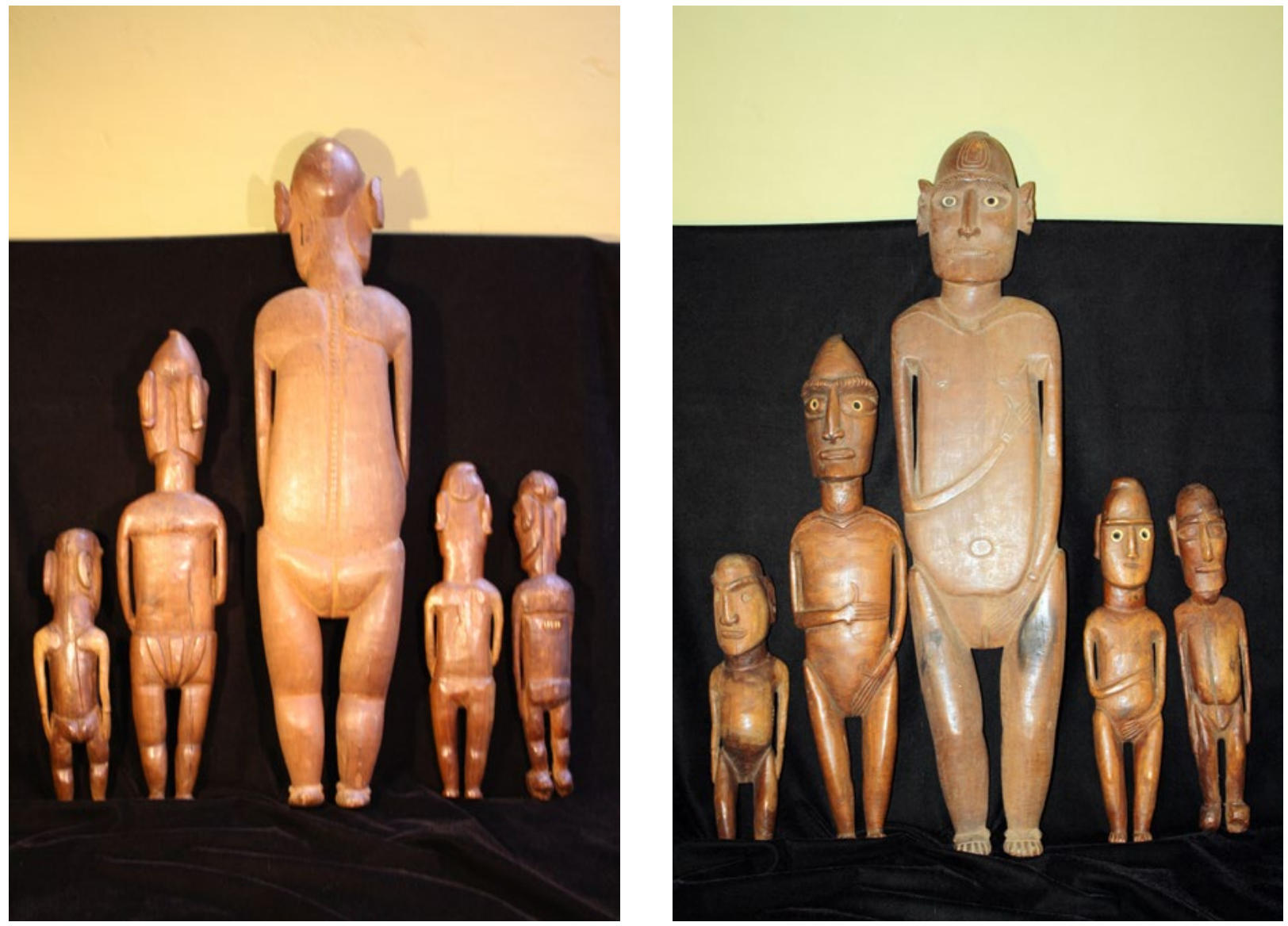

Figs. 24-25 GRupo de ESculturas fotografiadAs en el Museo EtNográfico, 2015. El PANEL Negro del fondo está A 60 CM DE ALTURA.
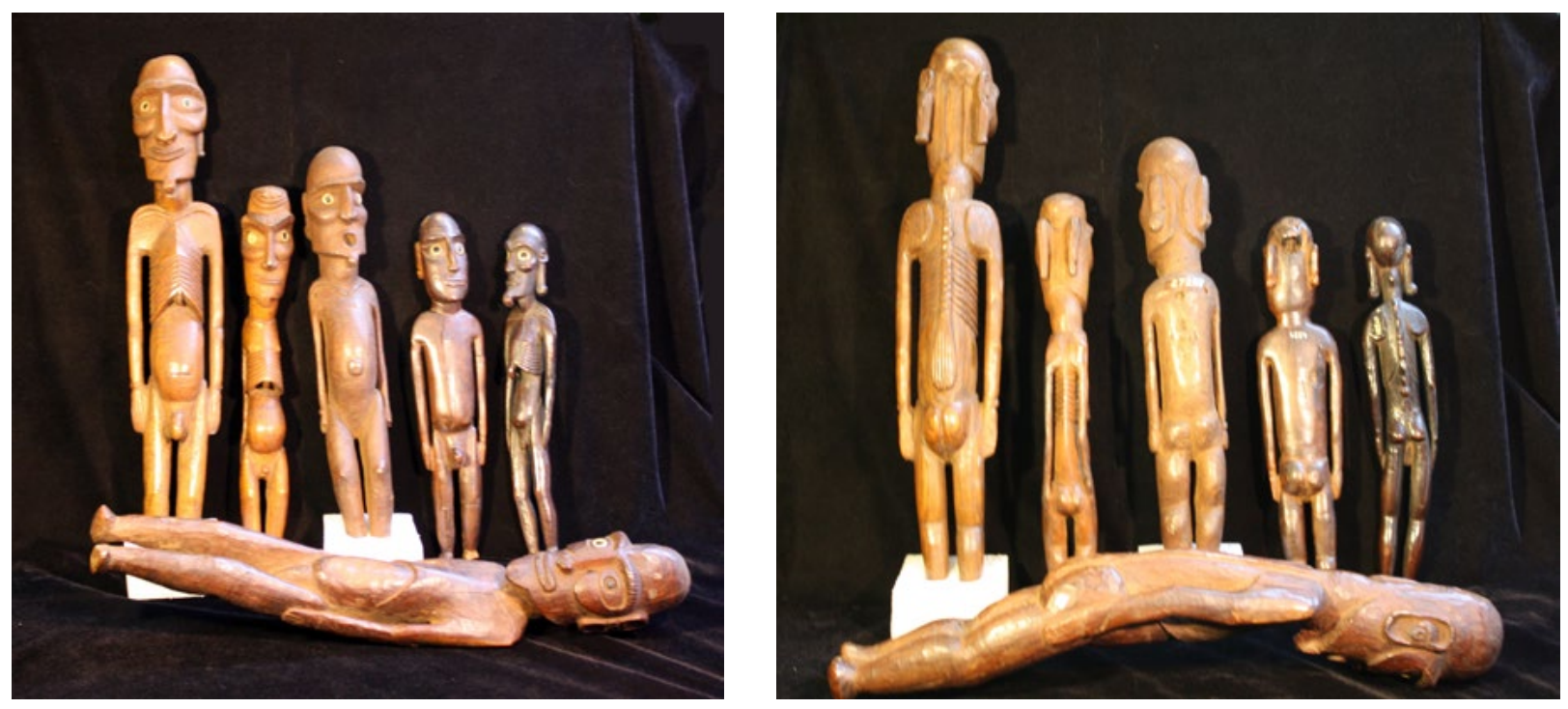

FIGS. 26- 27 SEgUNDO GRUPO DE ESCULTURAS FOtOGRAFIADAS EN 2015. 
antiguos en el tiempo, y hasta es posible que hayan sido hechas como resultado de una primera reconstrucción de la identidad, quizás antiguamente ni siquiera existieron. Ante la falta de evidencia, negativa o positiva, es imposible tener certezas. De todas formas salvo el citado libro de Stephen-Chauvet, un conocido coleccionista francés que reunió una importante cantidad de fotos de objetos en su libro de 1936, pocos les dieron importancia a las figurillas de madera hasta fines del siglo XX. Algunos autores publicaron grandes colecciones como J. Macmillan Brown con la conocida colección de Walter Knoche de Santiago de Chile, pero el conocimiento avanzó poco. Se suponía, y se sigue suponiendo, que las más antiguas figuras talladas de madera eran las llegadas en los primeros barcos europeos. Y que a su vez el interés por comprarlos de los viajeros hizo que fueran prototipos básicos de los cuales lo demás se copió y/o sirvió de fuente de inspiración en los años siguientes. Se asumía que los artesanos debían -y lo hacían- ajustarse a modelos fijos que llegaban en los pocos libros y fotos que había, copiando una y otra vez con más o menos calidad o libertad creativa.

Hoy se han hecho públicas colecciones llegadas en los primeros años del contacto y que hasta hace algunos años no eran accesibles o al menos no estaban publicadas, por lo que los artesanos no tenían acceso a esas fuentes documentales, como las figuras del Museo Pitt-Rivers, el Museo Nacional de Escocia o los objetos en Leningrado o Moscú, incluso buena parte de los de Harvard, o las que hay en grandes colecciones privadas. Mientras que las tallas del American Museum of Natural History, el Metropolitan Museum en Nueva York y el Musee de l'Homme de París se repitieron en los libros y luego en manos de los artesanos hasta el cansancio. Pero lo que sí es seguro es que los artistas pascuences no sólo copiaron los modelos iniciales, si no que continuaron una tradición aunque no sepamos cuando comenzó.

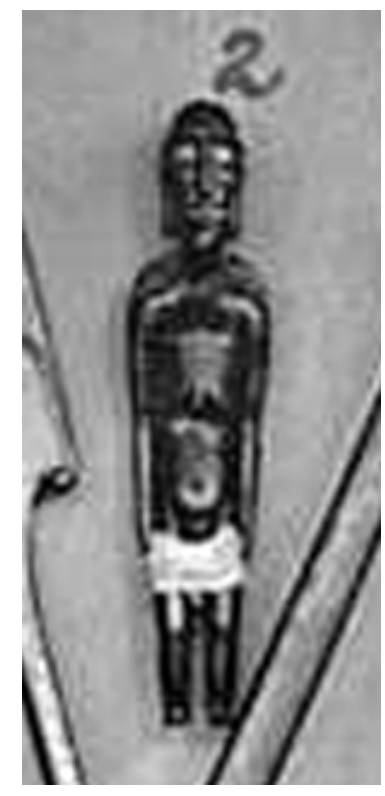

FIG. 28 PRIMER FIGURA HUMANA DE MADERA EN SER FOTOGRAFIADA Y DIFUNDIDA, 1868, UN MOAI KAVA KAVA, CON UNA FALDA PARA TAPARLE EL SEXO PORQUE ERA PARA UN OBISPO.

El estudio de estas piezas se vio complicado por los sucesos vividos en relación a las artesanías por la expedición de Thor Heyerdhal y ya muchas veces narrada y polemizada. En esa oportunidad hubo un evento mal manejado en que se cruzó lo académico con la difusión y el espíritu aventurero, en que la expedición fue engañada por un habitante local. Este los trasladó a una antigua caverna donde efectivamente se habían guardado cientos de objetos de piedra que no eran de gran antigüedad, pero no por eso dejaban de tener importancia para la historia del arte del siglo XX en la isla. Es verdad que era un timo, también que hoy forman el corpus de tallas de mitad del siglo XX más amplio del mundo. La polémica posterior, en especial el sacarlos sin declarar creyendo que eran antiguos, empañó todos los logros de la gran expedición, pero no podemos dejar de entender la presencia entre los objetos y sus detalles, de una enorme gama de continuidades.

Fue Heyerdhal quien hizo en dos de sus trabajos aportes significativos a este tema de las figuras en madera ${ }^{5}$ En su estudio sobre la heterogeneidad de la escultura rapanui remarcó la enorme variedad de objetos que existen y sus variantes formales, lo que es notable para una isla tan pequeña y con una escultura en piedra tan sistemáticamente reproducida a lo largo de siglos. Usó para demostrar su hipótesis figuras recuperadas antes de 1886, teniendo en cuenta el impulso que esta industria casera tuvo como un ingreso económico para los pobladores ante los entusiastas extranjeros. Pero el autor no dejó de tratar de demostrar otra teoría, el que los habitantes una y otra vez escondían sus esculturas -seguramente en cavernas-, las que iban reapareciendo de manera alternada, justificando la actitud del artesano que se las vendió. De todas formas eso no modifica ni aporta a la observación central: la marcada heterogeneidad de las tallas de madera en un lapso tan corto de tiempo. Esto se reafirma precisamente con las tallas del Museo Etnográfico.

5 Thor Heyerdhal, The Art of Easter Island, Doubleday Garden City, New York, 1975; idem, The Heterogeneity of Small Sculptures on Easter Island before 1886, Asian Perspectives vol. 22, no. 1, Pp. 11-15, 1979. 


\section{Análisis descriptivo de las tallas en madera}
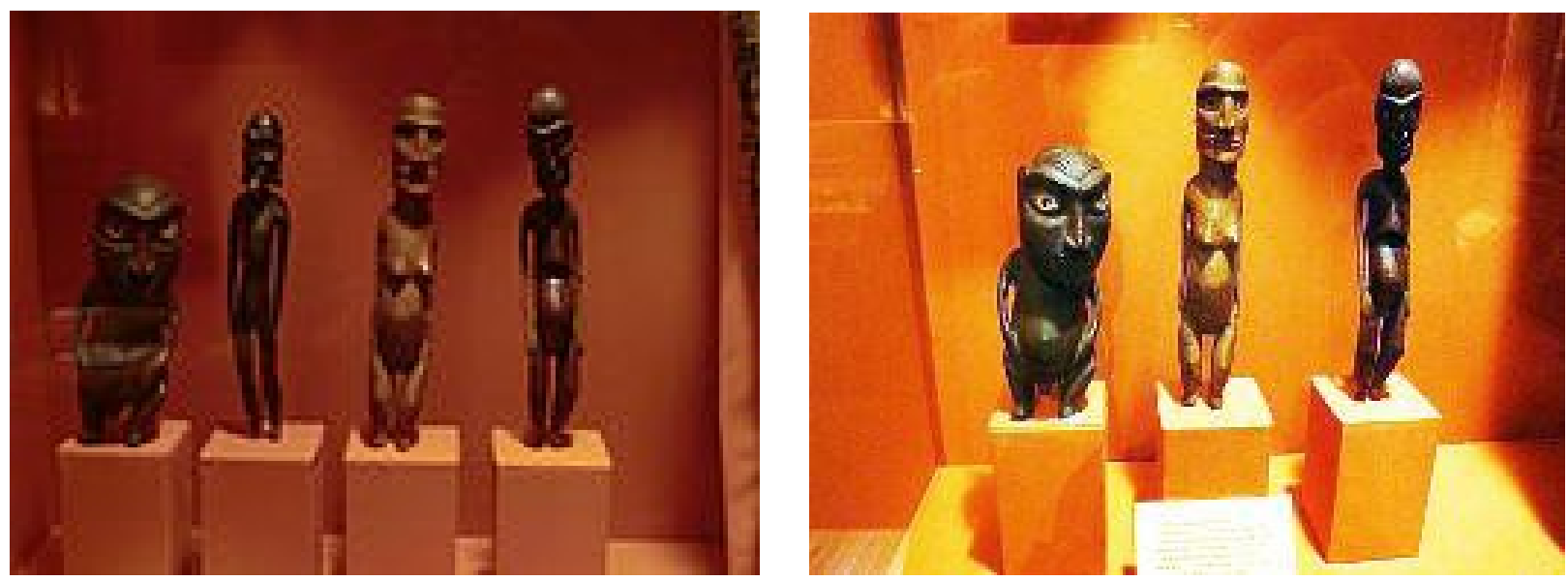

Fig. 29- 30 Conjunto de tallas exhibidAs en el Museo EtNográfico en feChas ReCientes (2010-2014) (FOTOS TOMADAS DE INTERNET).

\section{Escultura 1 (Figs. 31-32)}
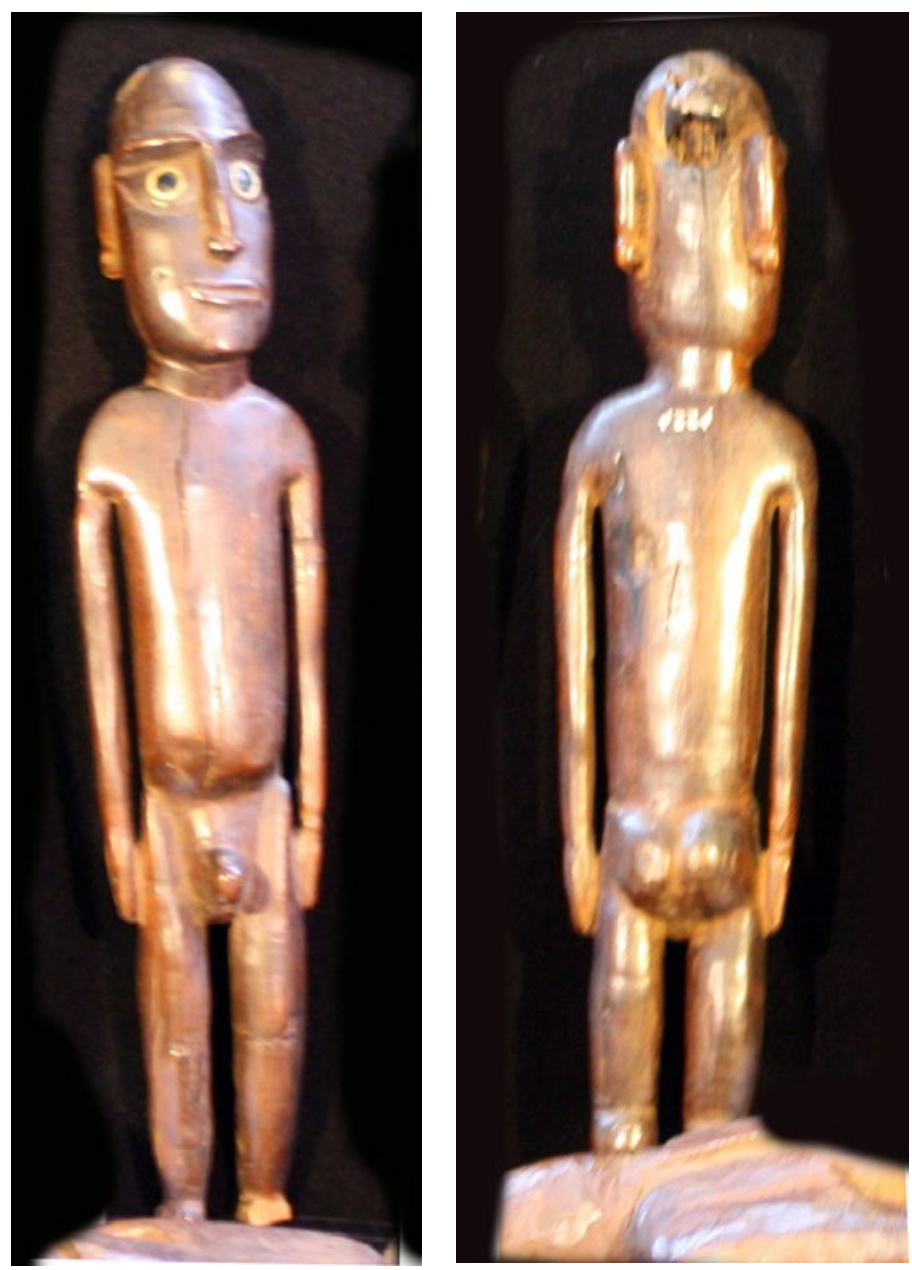

Figura de un Moai tangata, masculina, irregular en la postura, brazos con las manos pegadas al cuerpo, rodete en el cabello, ojos de hueso y obsidiana con la forma original alargada, cejas planas aunque no rectas ni marcadas, sin barba, sexo marcado, nalgas grandes, pátina destacada. Las curvas, en especial en la parte posterior le dan una imagen clásica y europeizante. Intenta sintetizar la escultura europea con las tradiciones de la isla. Resulta interesante que este tipo de figuras tenga en las que creemos más antiguas la forma de los ojos que sólo se descubrió en los moais para la década de 1970.

FIGS. 31-32 

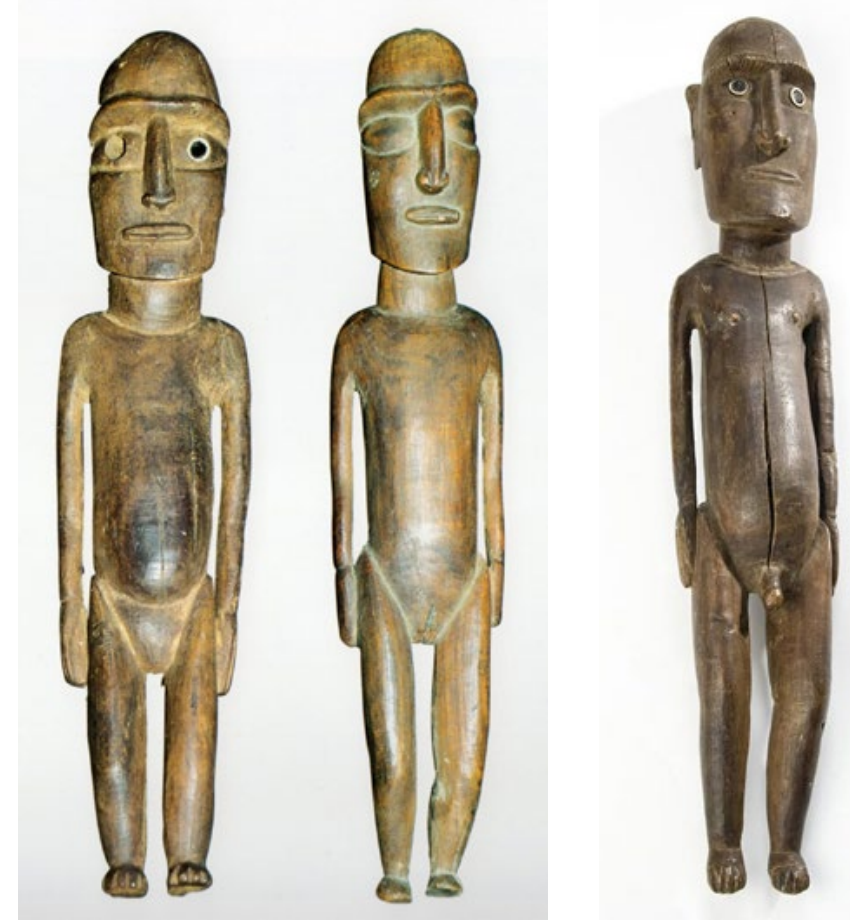

FIgS. 33- 34 IZQUIERDA Y CENTRO: FIGURAS ASEXUAdAS DEL MUSEO ENGLERT EN HANGA ROA CON CABEZA-MOAI Y DIFERENTES TIPOS DE OJOS, RESULTADO DE LA UNIÓN DE LAS DOS TRADICIONES ARTÍSTICAS EN EL SIGLO XIX. A LA DERECHA TALLA

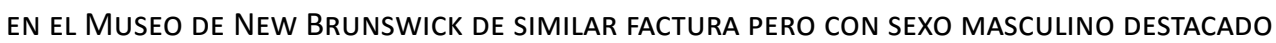

(FOTOGRAFÍA MORDO 2002, PAG. 128).

\section{Escultura 2 (Figs. 35-36)}
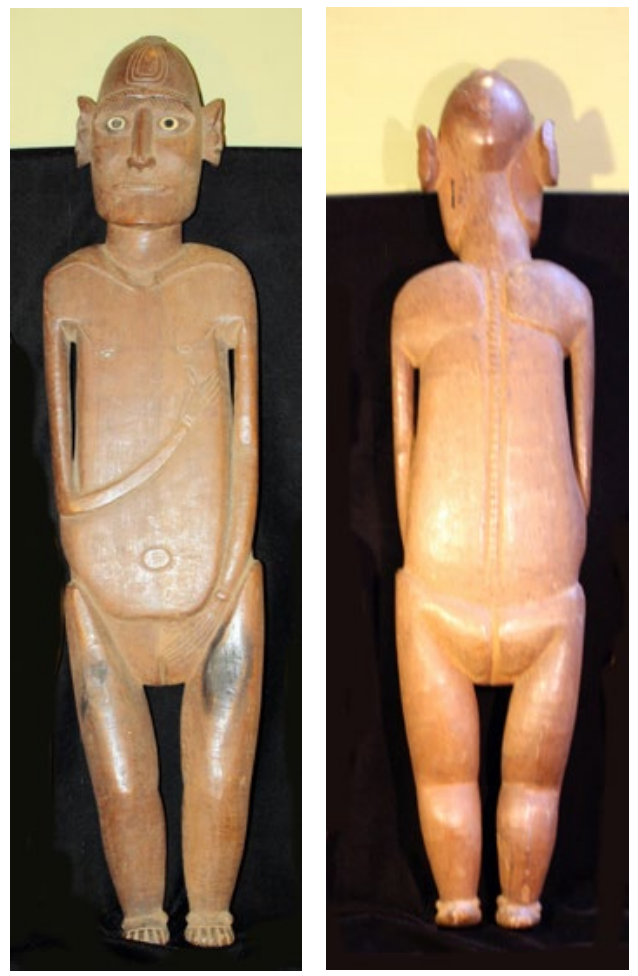

FIGS. 35-36
La pieza más grande de la colección, un Moai papa, sexualidad femenina, similar a una antigua fotografía que reproducimos abajo y a otras de diversas colecciones, columna vertebral destacada, cabeza rapada y ornamentada, ombligo saliente, ojos de hueso y obsidiana, orejas estiradas, pies pequeños. Nótese el brazo derecho curvo con la mano abierta y sosteniendo un objeto, ambos muy simples en el tallado y la mano abierta sobre el corazón con dedo pulgar levantado, cráneo con los huesos marcados. Senos muy planos y caídos, el estómago es redondeado pero plano, desde atrás la figura es asimétrica. Cejas en forma de T. Si bien ingresó en 1938 desde el Museo B. Rivadavia es muy posible que sea de finales del siglo XIX. Hay similitudes en la forma de cejas-nariz a una pieza publicada por Stephen-Chauvet. Hay ejemplos de Moai papa conocidas y publicadas realmente antiguas, $\mathrm{y}$ ambas tienen una mano sobre el sexo y en varias el brazo izquierdo en el pecho ${ }^{6}$.

\footnotetext{
${ }^{6}$ Adrianne L. Kaeppler, Rapa Nui art and aesthetics, (E. Kjellgren edit.) Splendid Isolation: Art of Easter Island, Splendid Isolation, pp. 32-41, Nueva York, 2002, figs. 11 y 12.
} 

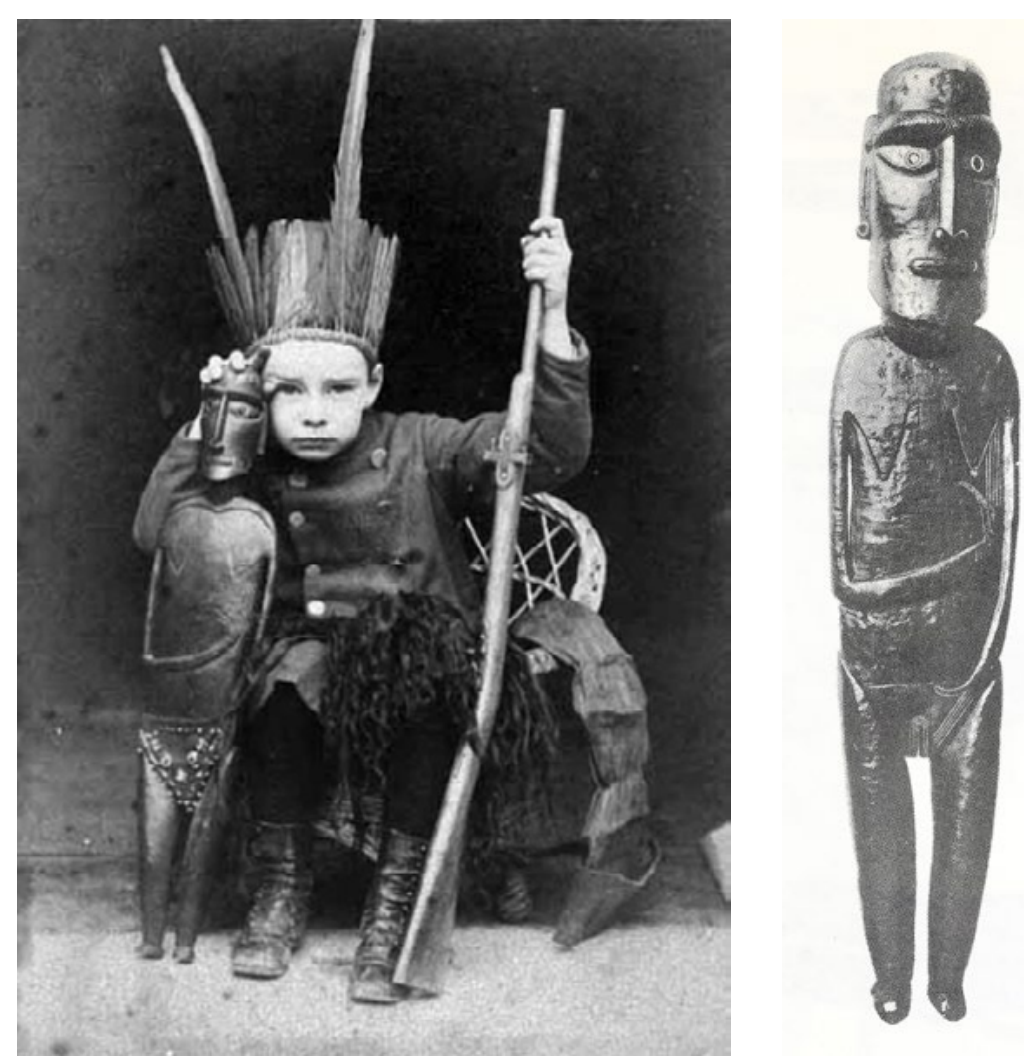

FIGS. 37- 38 ANTIGUA FOTOGRAFíA DE ORIGEN DESCONOCIDA PERO EXTERNA A LA ISLA MOSTRANDO UNA FIGURA SIMILAR

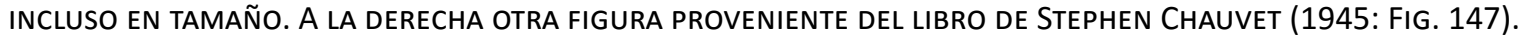

\section{Escultura No. 3 (Figs. 39-40)}
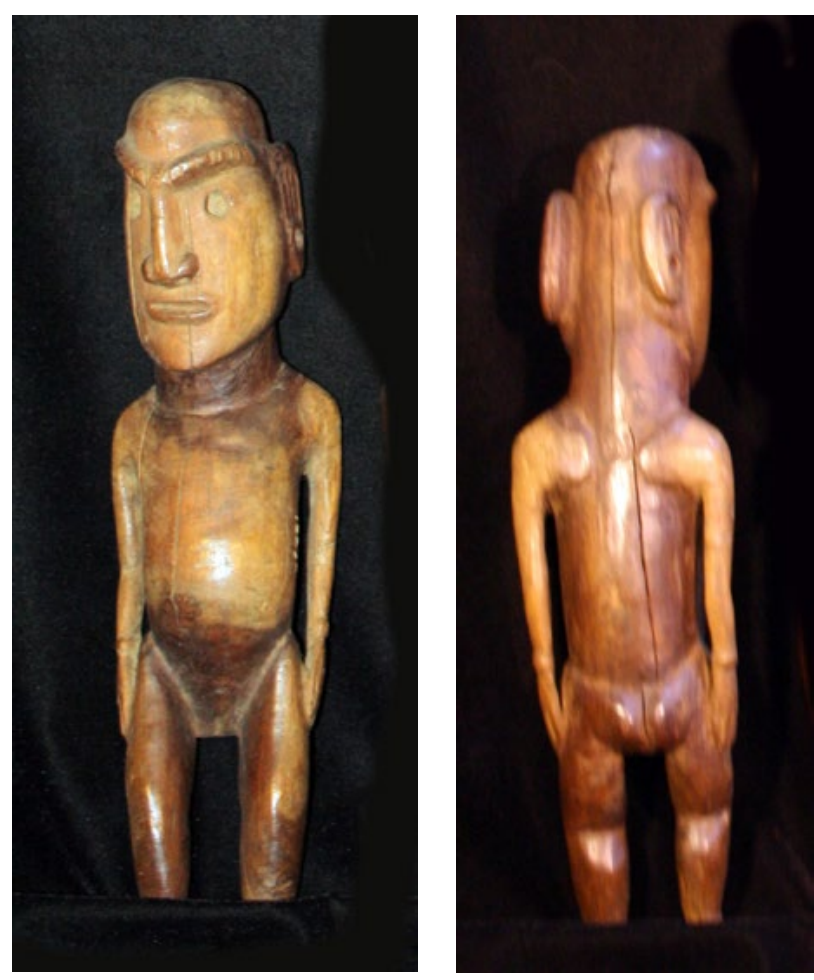

FIGS. 39-40
Pieza de catálogo ME 6128, $31 \mathrm{~cm}$ de altura. Moai tangata, pies no visibles, poco marcado el sexo femenino de posible hechura posterior para valorizarla, con las extrañas orejas estiradas hacia la nuca, hombros fuertes, cejas con marcas, ojos redondeados, cuello ancho, presenta fisuras verticales. Manos laterales sobre el cuerpo, pátina intensa. Se encuadra dentro de un amplio grupo poco definido de representaciones humanas de bulto. 


\section{Escultura No. 4 (Figs. 41- 43)}
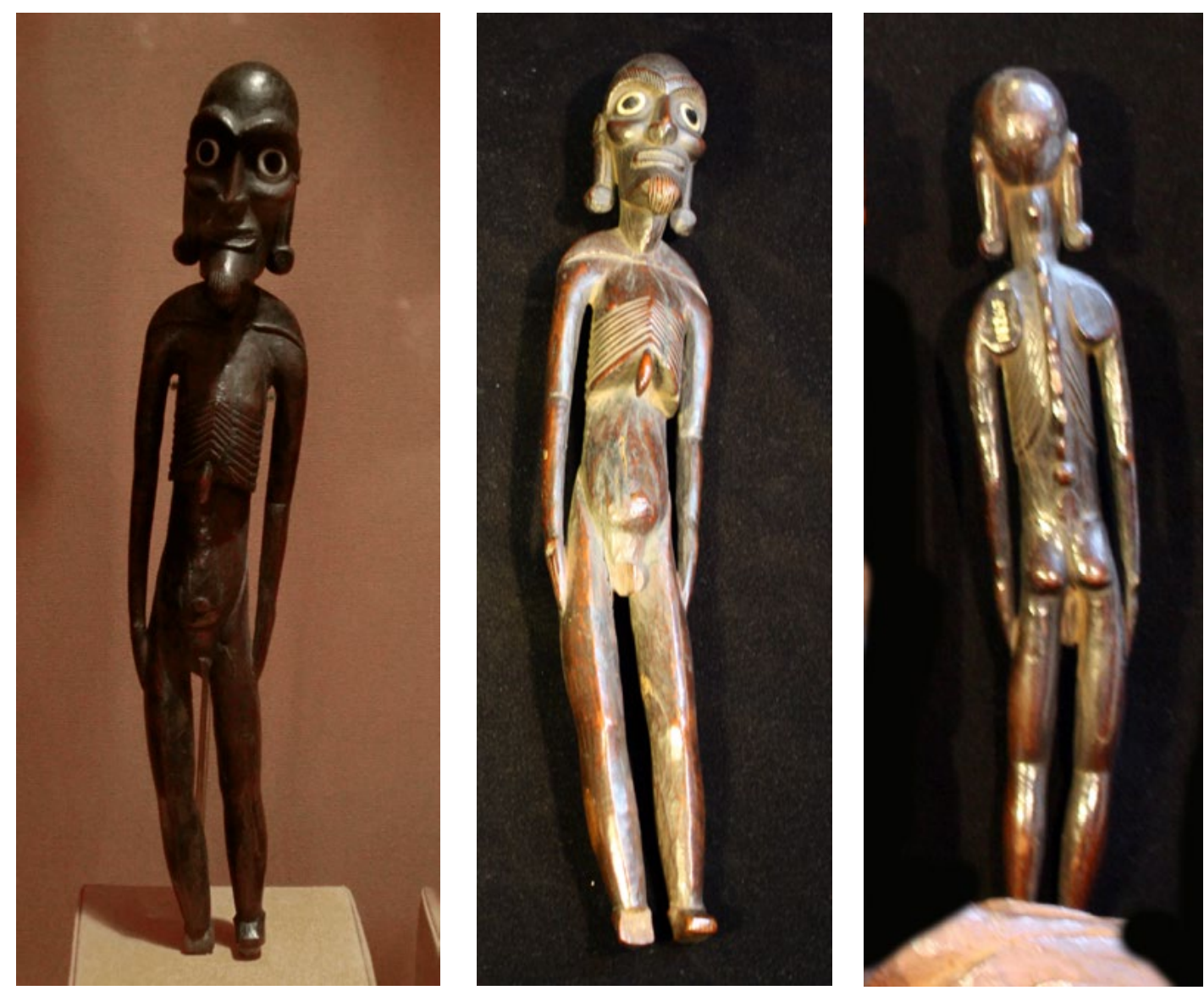

FIGS. 41-43

ME 6124. Ingreso por compra en 1914, de $40 \mathrm{~cm}$ de altura. Moai Kava kava de excelente factura, posiblemente lo mejor de la colección. Se destaca su cuerpo descarnado, barba saliente, esternón con las costillas visibles, vértebras bien definidas, sexo pequeño, ombligo circular, cresta en el esternón, manos asimétricas, piernas dobladas ligeramente casi sin marcas de rodillas ni tobillos. Cejas prominentes, pómulos salientes. Ha estado en exhibición en varias oportunidades en el museo. 

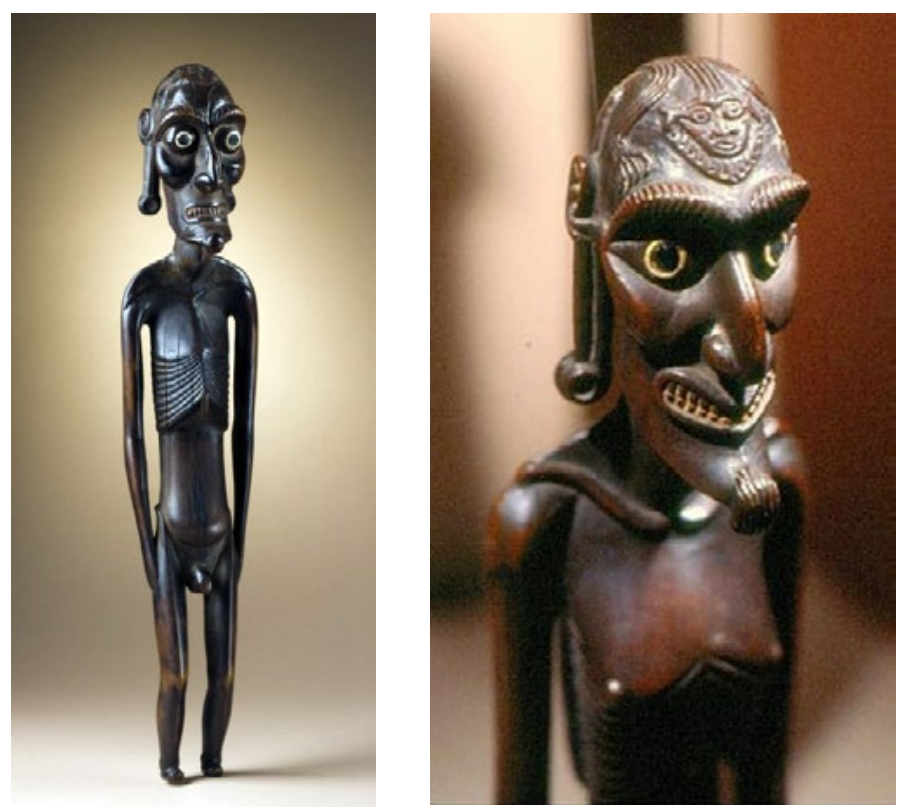

Figs. 44- 45 Moai Kava kava en la colección del los Angeles County Museum of ART.

Escultura Nro. 5 (Figs. 46- 47)
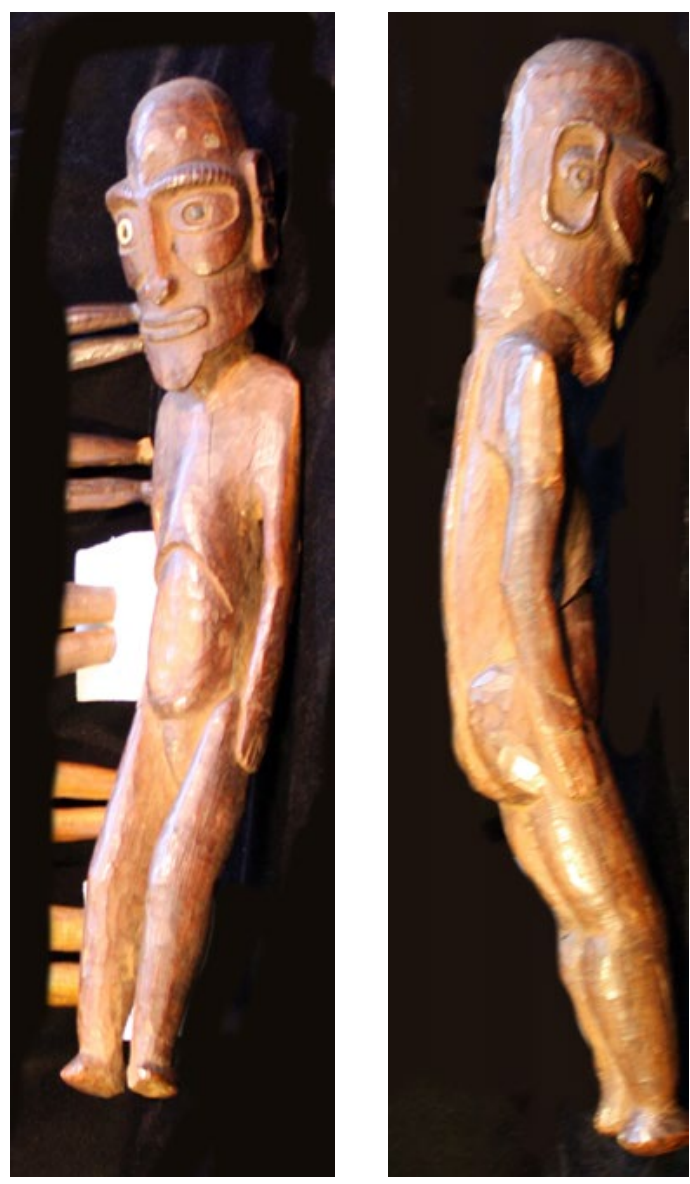

ME 6123, pieza muy larga de $63 \mathrm{~cm}$, donada por la Academia de Filosofía y Letras de Santiago de Chile en 1914 (la ficha del museo indica "Compra en Chile"). Es además de única en su postura ya que no puede mantenerse de pie, también lo es por el tipo de barba, con orejas muy peculiares y poco comunes, panza remarcada hacia arriba, tres círculos en la frente y posible tatuaje bordeando los pómulos, falta un ojo de hueso y la forma externa es similar a la factura de la oreja. Los pies son simples muñones como si no fuera necesario estar de pie. El estómago está rehundido pero no marca las costillas, parecería una pieza muy moderna y de baja calidad. 
Escultura No. 6 (Figs. 48-49)

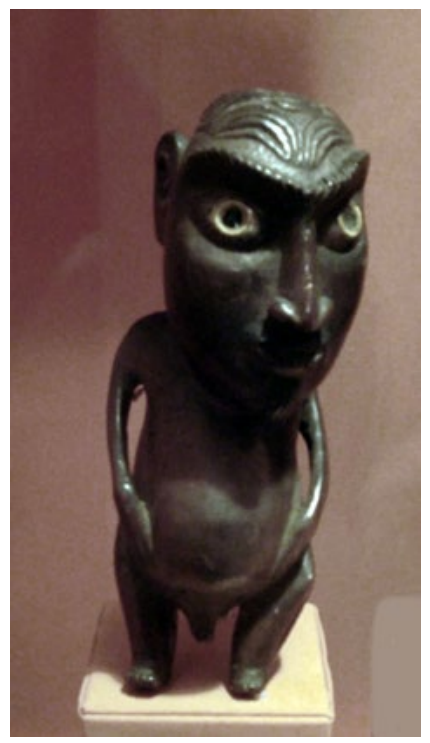

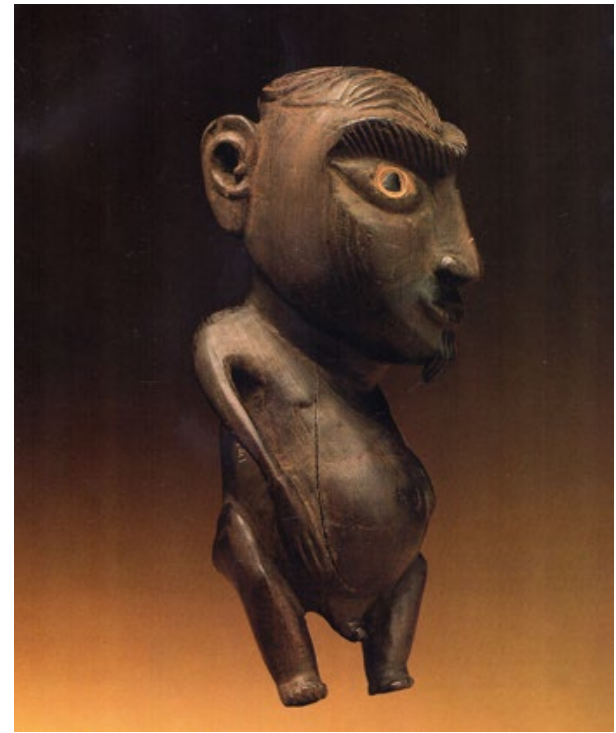

FIGS. 48-49

Una talla conocida y muy significativa de la colección ha sido mostrada muchas veces en Internet. Reúne todos los elementos clásicos de las figurillas y destacamos los ojos estirados en la antigua tradición. Es común en Oceanía. Cabeza con tatuajes, sexo masculino marcado, la nariz típica del final del siglo XIX, pestañas marcadas, manos hacia el sexo, sin cuello.

Escultura no. 7 (Figs. 50- 51)
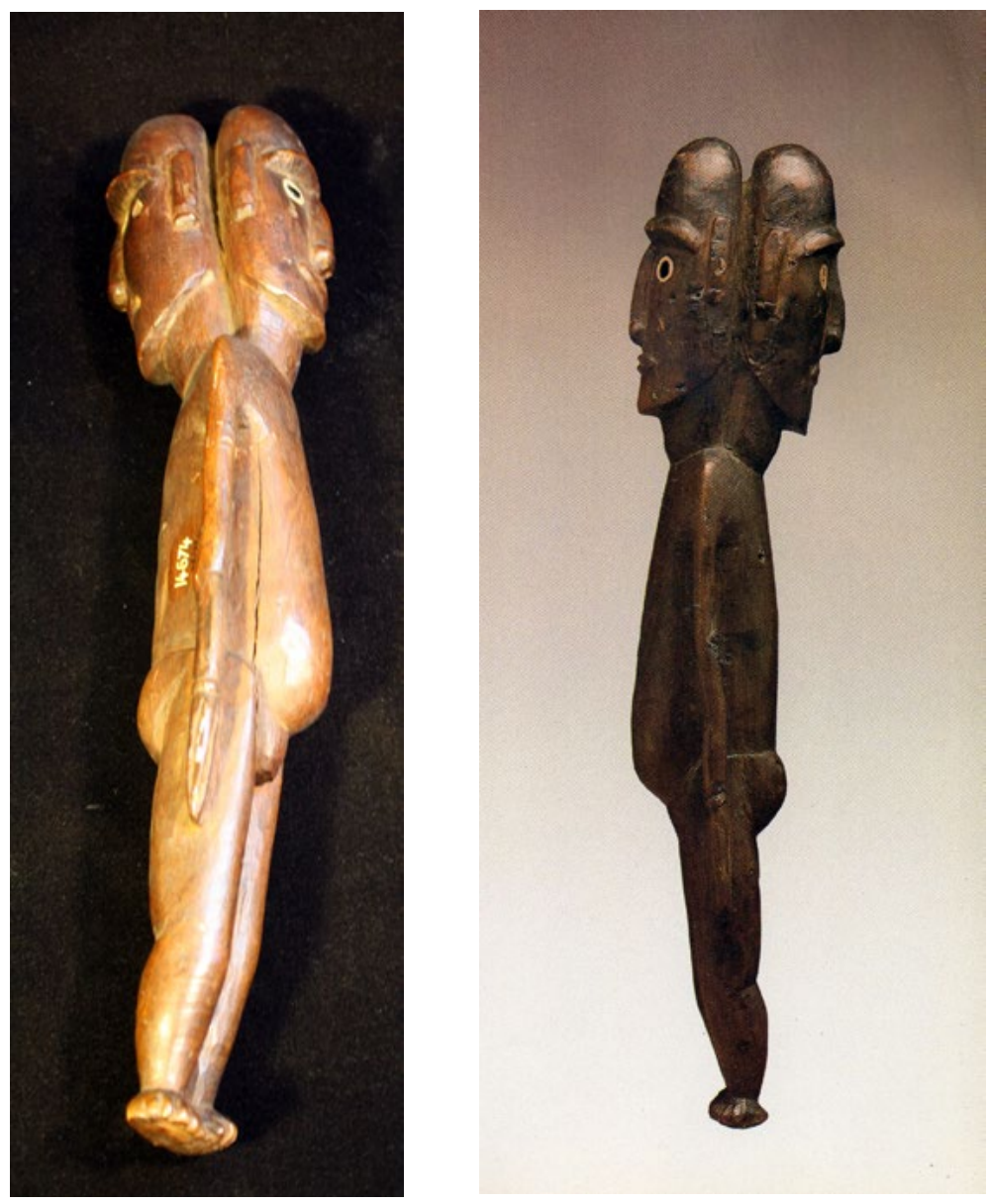

ME 6130, Moai aringa de $44 \mathrm{~cm}$ de altura, un cuerpo con dos cabezas mirando hacia lados opuestos. El cuerpo está hacia uno de los lados lo que coincide en todos los detalles, sexo masculino marcado, piernas unidas, cráneos pelados, orejas alargadas pero sin marcas ni tatuajes. Es diferente a las conocidas ya que o miran ambas cabezas de frente o hacia ambos lados de un cuerpo perpendicular a ambas. Parecería una escultura que aprovechó la forma de una madera pero sin ajustarse a un modelo que pese a las variedades tenía una tradición, o un arreglo tras un error. Ingresado por compra en $1913^{7}$.

$\overline{7}$ A. Metraux (1940), op. cit. pag. 249

FIGS. 50-51 

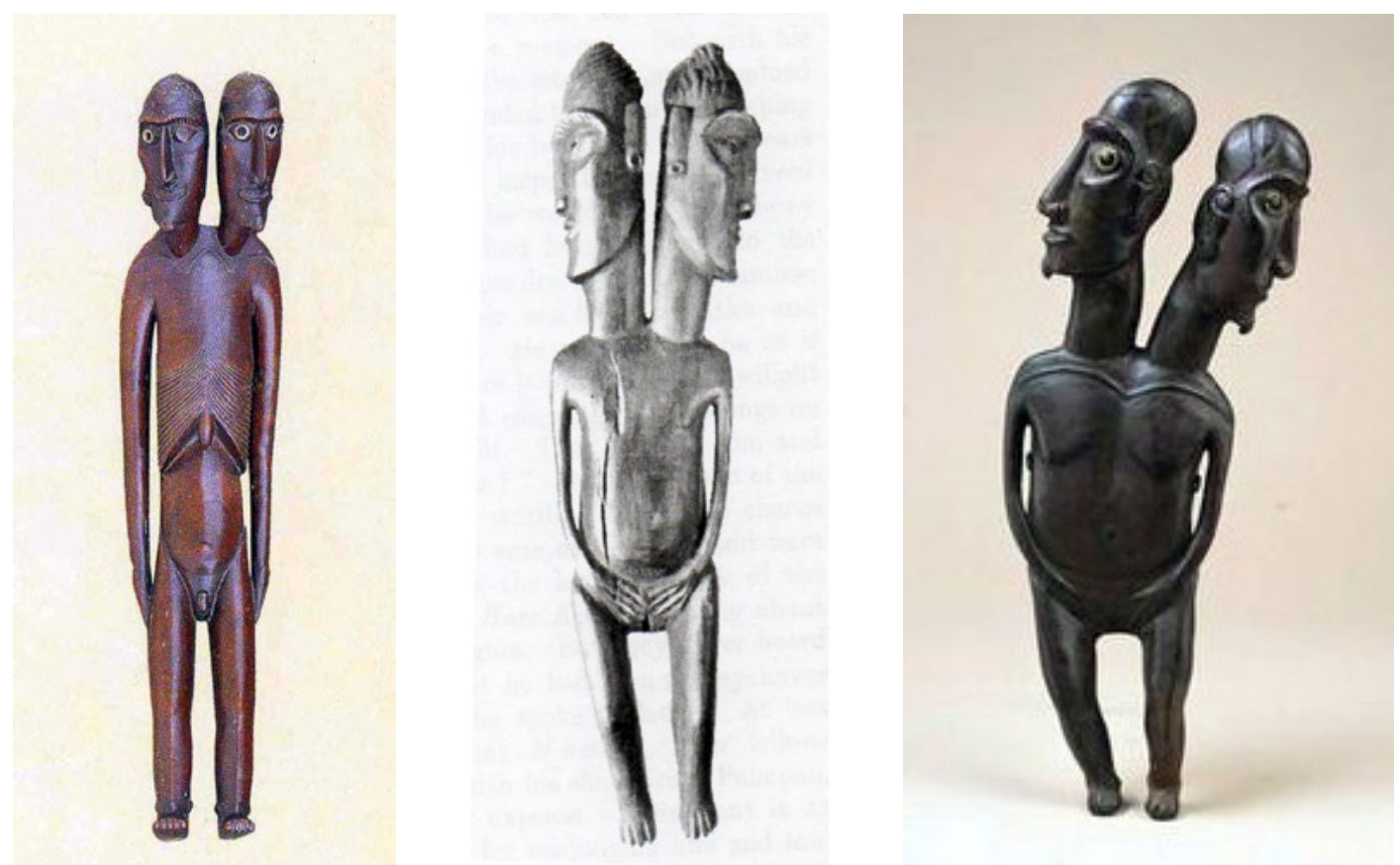

FigS. 52- 54 TRES MOAI ARINGA, BICÉFALOS POR DEFINICIÓN, QUE MUESTRAN LA DIFERENCIA CON EL DEL MUSEO ETNOGRÁFICO (Fotografías del Museo de La Rochelle, Macmillan 1927 y Museo Nacional de ISRAel).

\section{Escultura Nro. 8 (Figs. 55- 56)}
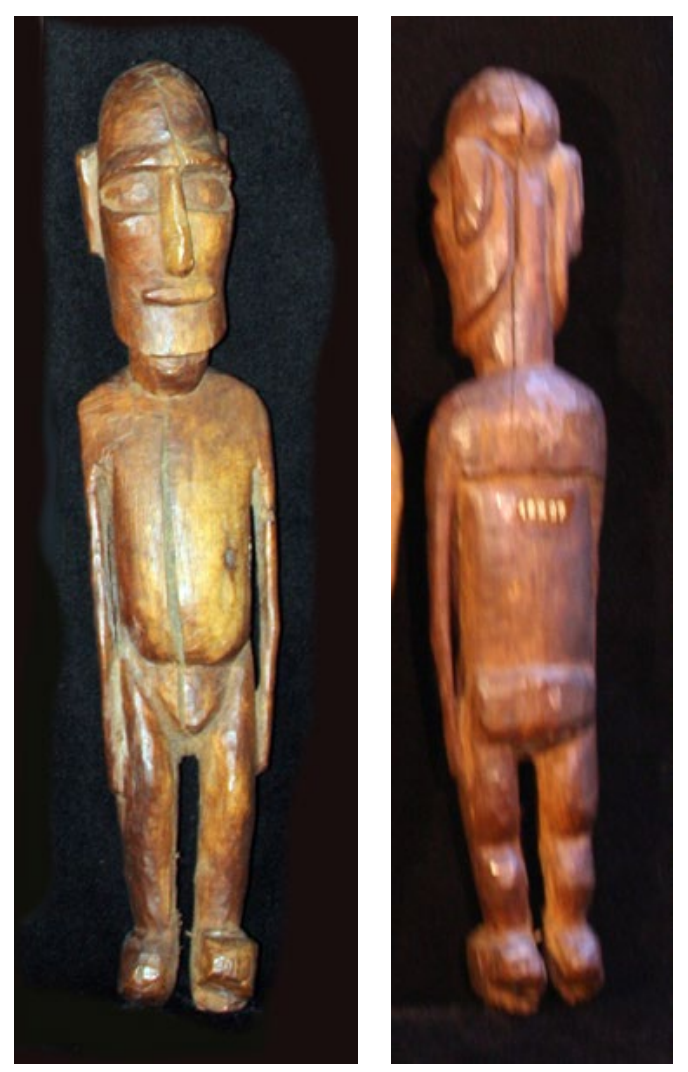

Esta es una de las tallas de menor calidad en el sentido que parece que no ha sido terminada o que tras hacer una cabeza de calidad las piernas y pies quedaron mal por problemas de la madera. No tiene sexo, los pies son diferentes y uno sin terminar, muy simple, brazos muy irregulares, ojos salientes y no para colocarle hueso con obsidiana. Hay similares conocidas y parecería ser casi descartes. 
Escultura no. 9 (Figs. 57- 59)
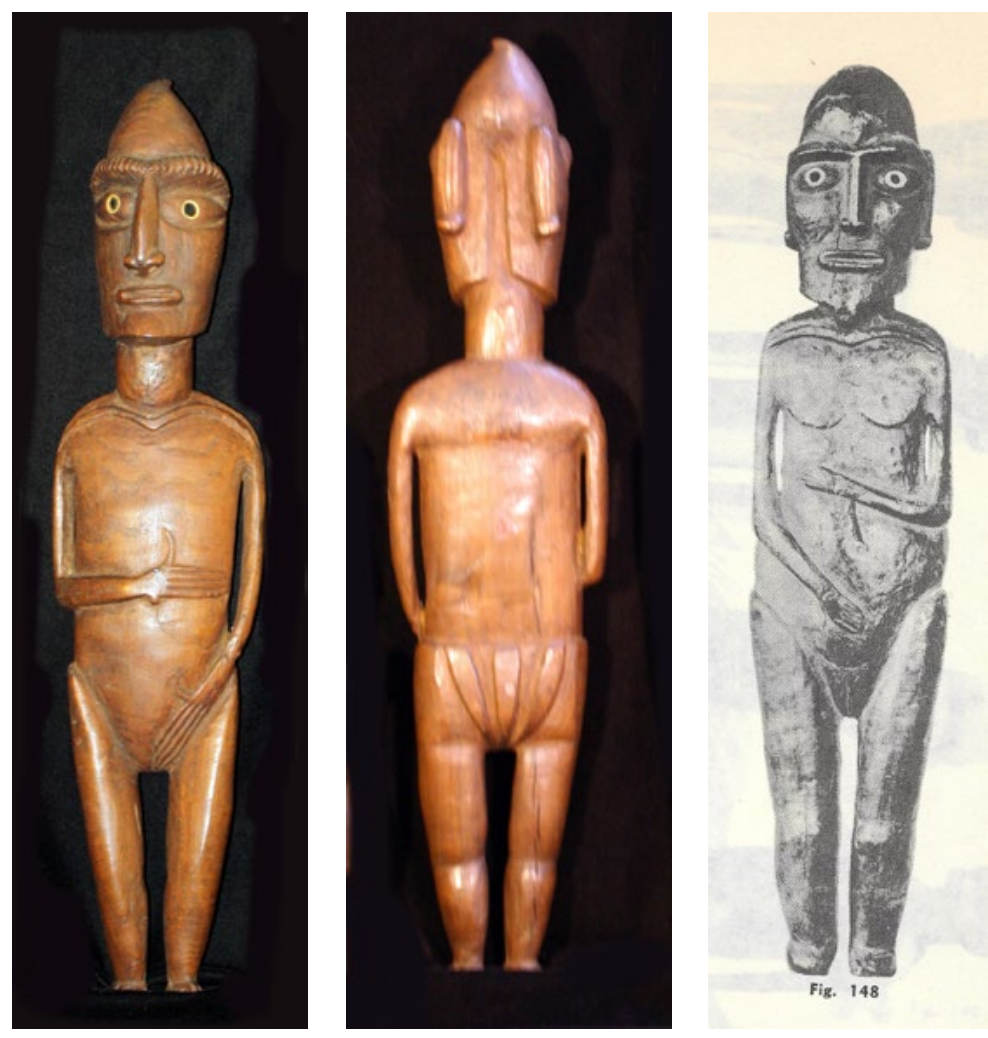

Pieza muy particular ya que reúne elementos conocidos de los Moai papa femeninos, plano, una mano hacia abajo y otra arriba hacia un seno, no termina de cerrar en los detalles. El faldellín en la parte posterior es único y termina con una pieza atada con hilo delante, aunque le remarcaron el sexo posiblemente para hacerla vendible. La postura del dedo es la tradicional. Clavículas muy marcadas completando el frente le falta el ombligo no siempre presente. Es una excelente pieza más al ser poco tradicional. Reproducimos de Stephen Chauvet un ejemplo muy similar ${ }^{8}$.

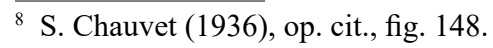

FIGS. 57-59

Escultura no. 10 (Figs. 60-61)

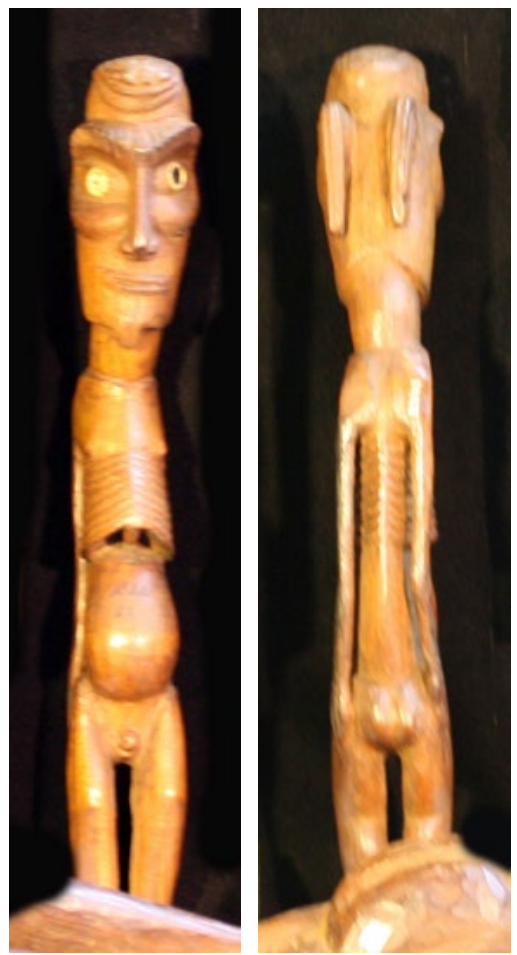

FIGS. 60-61
ME 6121, comprado en 1915 de $57 \mathrm{~cm}$ de altura. Un Moai kava kava con caja torácica y costillas muy marcadas, estómago ahuecado (caso muy poco habitual), frente con tatuajes, masculino con sexo poco marcado, orejas en la nuca, brazos atrás, extremadamente delgado en la proporción del cuerpo, demasiado trabajo, posee una capa de posible barniz muy ligero. Cabeza alargada y grande, ojos muy simples, parece haber sufrido una fuerte influencia de la escultura europea de bulto. Resulta una exageración de los Kava kava tradicionales quizás con espíritu comercial. 
Escultura Nro. 11 (Figs. 62- 63)
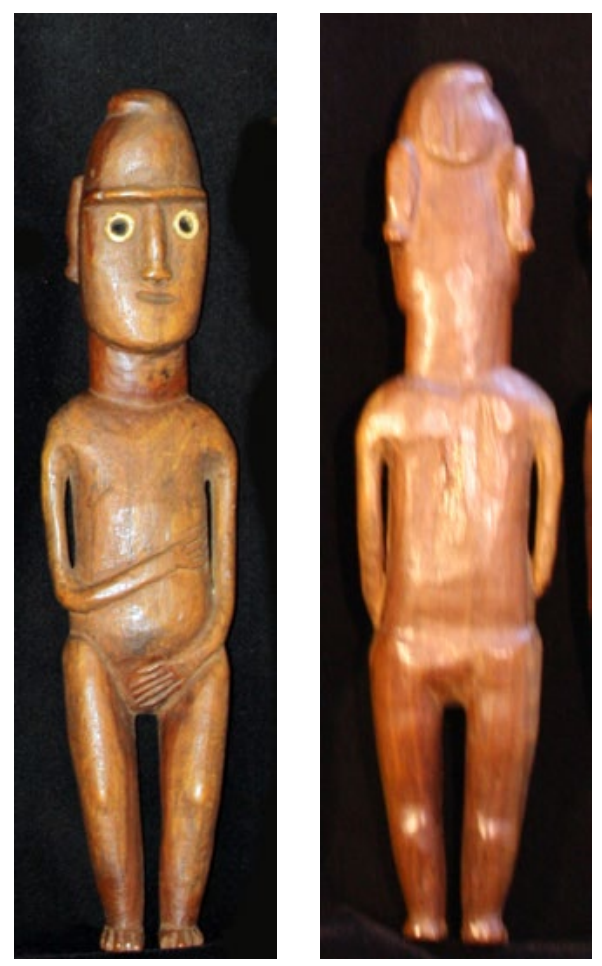

FIGS. 62-63

\section{Escultura no. 12 (Figs. 64- 65)}
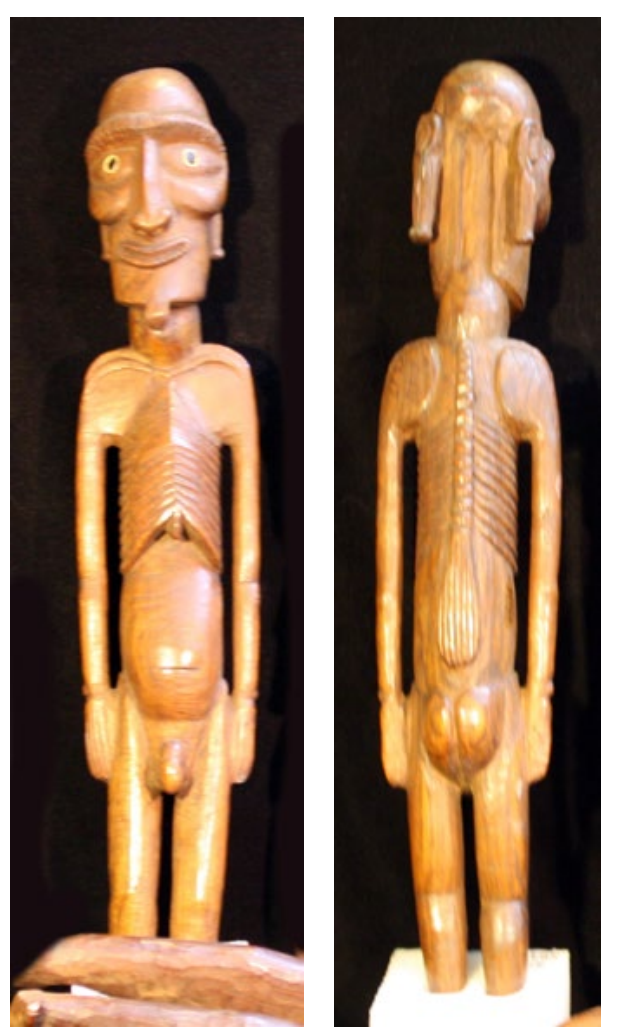

Figura de bulto, piernas redondeadas, mano, sin ombligo, rostro Occidental aunque con las cejas-nariz tradicional, sin tatuajes, cuello grueso y alto, parecería haber unido la tradición de la postura de las manos de los Moai tangata femeninos con una pieza europeizante que tiende a mantener una cabeza-moai tradicional.

FIGS. 64-65 


\section{Escultura Nro. 13 (Fig. 66)}

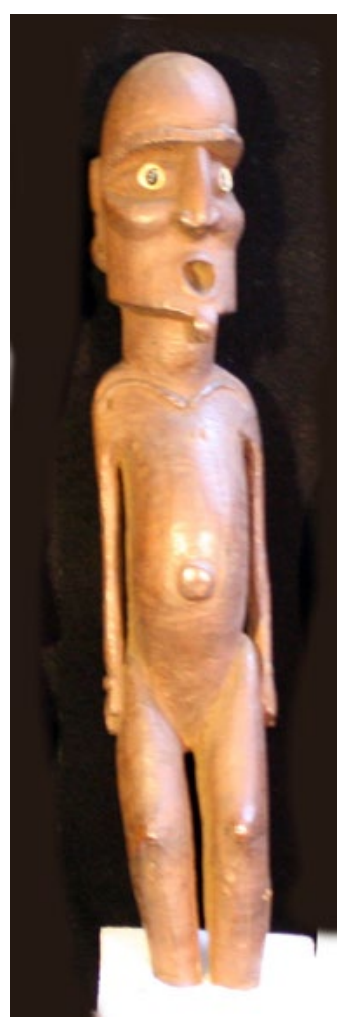

FIG. 66
ME 6129, de $45 \mathrm{~cm}$, ingresado en1921. Figura de tallado simple, boca circular ahuecada, brazos muy delgados y mano retocado o retallada, orejas largas que llegan a la nuca, ombligo saliente y gordo, rodillas y clavículas marcadas. No tiene evidencia de sexo.

\section{Escultura Nro. 14 (Figs. 67)}

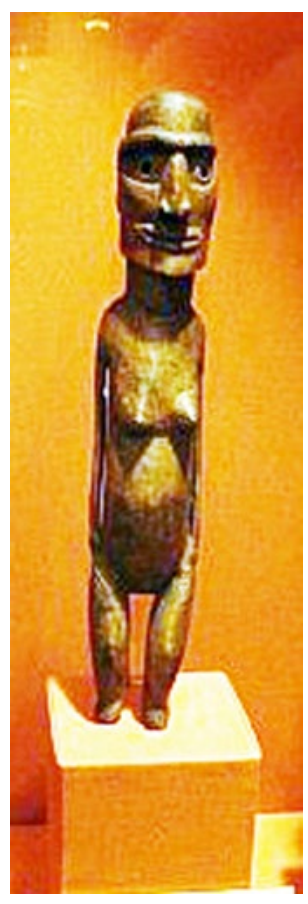

FIG. 67
Pieza en exhibición, Moai papa, femenina, sin panza, senos grandes, boca muy marcada y redondeada, cejas unidas aunque curvas brazos en extremo alargados, piernas cortas, ojos de hueso y obsidiana, ombligo y estómago normal. Tiene elementos que conjugan la tradición de la cabeza tipo moai con el cuerpo clásico europeo, en especial los senos que habitualmente son planos. Es extraño encontrar este tipo de piezas que unen a lo femenino con cuerpos cilíndricos de esta manera. 
Escultura no. 15 (Fig. 68)

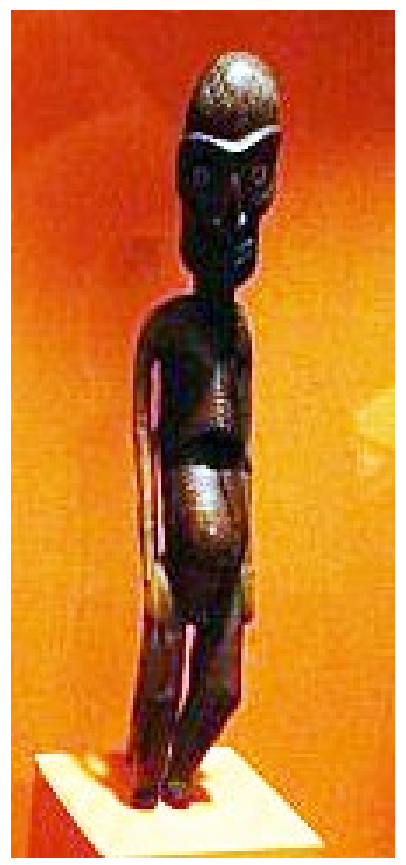

FIGS. 68
Moai Kava kava, expuesto por el Museo, sin datos concretos ni otras fotografías. Se destaca el pecho saliente, las piernas muy quebradas, el sexo masculino y brazos muy extensos.

\section{Conclusiones}

Las quince figuras forman la colección completa que hay en el Museo Etnográfico de la Universidad de Buenos Aires tal como pudimos, con muchas dificultades, analizar. El objetivo era presentarlas para que puedan ser usadas e identificadas en el concierto universal de esculturas de Pascua. Dadas las características del museo y su vida es probable que haya otras mal clasificadas, o simplemente no accesibles al estar entre las similares de la gran colección de Oceanía; no descartamos eso. Como conjunto se reafirman varias ideas ya consensuadas: las estatuillas son resultado de un proceso de adaptación del arte europeo y la tradición rapanui, y es en los rostros o en la extrema delgadez donde más se ha conservado. En los cuerpos hay una evidente trayectoria iniciada en el siglo XVIII -no sabemos si es anterior- de mostrar cuerpos erguidos, de bulto, cilíndricos y no planos ${ }^{10}$. Pero esto igualmente no está claro ya que entre las esculturas llevadas por James Cook hay una que simplemente representa una persona bien alimentada, de bulto, erguida, aunque con una cabeza bien local y no de tipo moai, hierática. Esto puede abrir otra posible veta de la historia del desarrollo de la escultura local, en que la cabeza-moai haya sido colocada precisamente para darle, ante la mirada extranjera, una síntesis con los colosos de piedra.

No sabemos cómo eran las tallas pre-Contacto, pero al menos las más antiguas que se preservaron muestran que es posible que se haya tratado en el siglo XIX tardío de exagerar ciertos rasgos, como en los Kava kava, para satisface el gusto exótico extranjero. Por eso hay más y por lo tanto fue mayor la cantidad conservada. No llegó al Museo Etnográfico nada en piedra, en tela vegetal (rapa), no hay los peculiares hombre-pájaro (Tangata manu), ni los pendientes, ni las hachas de obsidiana tan comunes, ni los extraordinarios moko (lagartos). Es decir que quienes formaron la colección juntaron lo que pudieron o lo que fue donado (aunque parte fue adquirida), sin hacer una elección o selección siquiera de lo accesible en su tiempo. Pensando como coleccionistas, en el viaje de Marcelo Bórmida y su "Expedición” parecería que se hizo

10 Dan Hicks, Sue Hamilton, Mike Seager, Thomas y Ruth Whitehouse, Easter Island and Pitcairn Island (Dan Hicks y Alice Stevenson edits.), World Archaeology at the Pitt Rivers Museum: a characterization, Archaeopress, Oxford, 2013 , pp. 564-572. 
aun menos para aumentar los objetos. No porque tuvieran reparo en comprar nada, o buscar cosas antiguas ya que en su museo había miles de piezas llegadas de la misma forma; no era precisamente por respeto a la cultura local. Deben haber considerado que ya todo era "mestizo" y por ende culturalmente degradado.

Resulta finalmente interesante comparar la colección del museo con otras formadas en la misma época, inicios y hasta la mitad del siglo XX, como la de Knoche de Santiago de Chile, en donde está representada toda la variedad aquí existente.

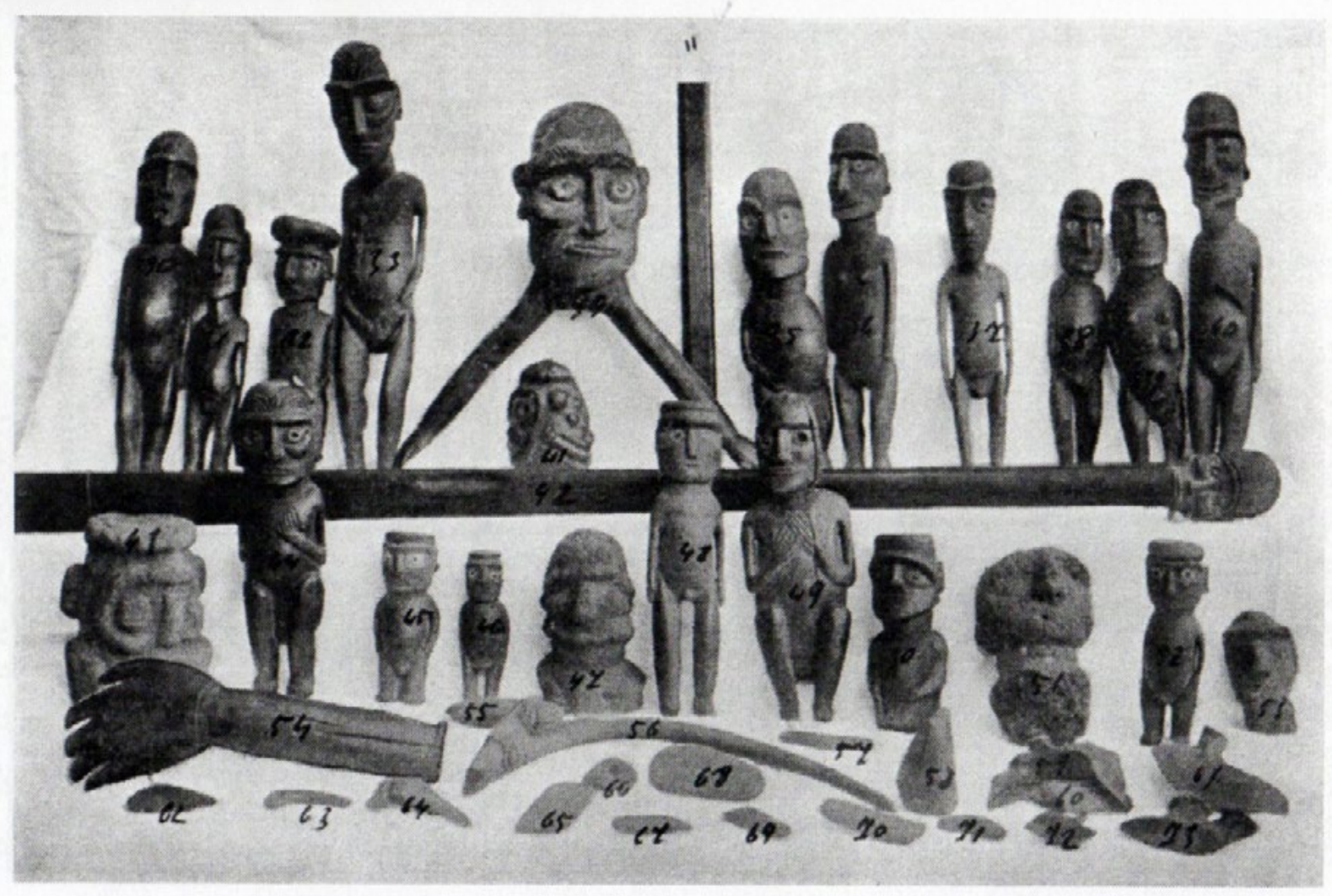

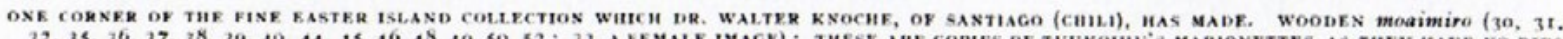

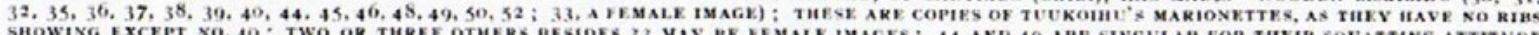
ASD THEIR X

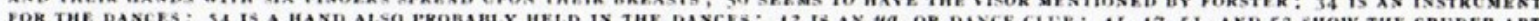

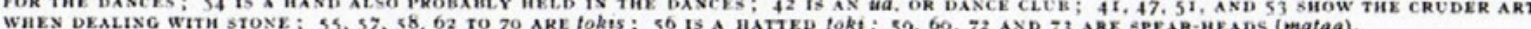

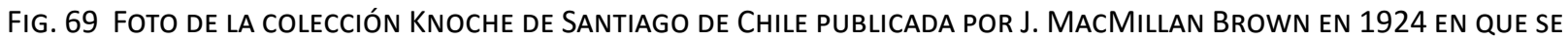
ENCUENTRAN FIGURAS SIMILARES A LAS DEL MUSEO ETNOGRÁFICO FRUTO DEL ARTE DE SU TIEMPO. 